\title{
OSTEOPOROSIS IN THE COMMUNITY: FINDINGS FROM A NOVEL COMPUTERIZED REGISTRY IN A LARGE HEALTH ORGANIZATION IN ISRAEL
}

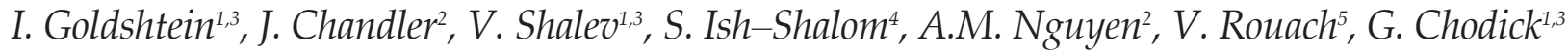

\begin{abstract}
Background: Osteoporosis is a growing public health concern due to its rising prevalence and excess morbidity and mortality. Automated patient registries have gained great importance in health and disease management of major chronic diseases, but are rarely used in osteoporosis. Objectives: To construct an automated, population-based registry of osteoporosis. Setting: The electronic medical records and pharmacy databases of a 2 million member health organization in Israel (Maccabi Healthcare Services). Methods: Included in the registry were adults who were diagnosed with osteoporosis diagnosis, had major osteoporotic fractures, or purchased relevant medications, between 2000 and 2013. In addition, we included patients with low bone density as extracted from over 140,000 measurements reports, using an automated optical character recognition (OCR) system. Two-thirds of the cases were validated by more than one inclusion criterion. Results: A total of 118,141 osteoporosis patients were identified. The point prevalence of osteoporosis among members aged 50 or above in 2013 was 19\%. The mean age at registry entry was 62 $(\mathrm{SD}=12)$ and $66(\mathrm{SD}=14)$ years for females and males, respectively. The highest annual risk of developing osteoporosis (27 per 1000) was recorded among females aged 65-75. In $28 \%$ of the patients, there was no indication of treatment with osteoporosis therapy. Conclusions: To the best of our knowledge, this is one of the first real-world automated registries of osteoporosis. Similar registries may provide valuable data for real-time monitoring of trends, quality of care, and outcome research in osteoporosis and its complications.
\end{abstract}

Key words: Osteoporosis, registry, prevalence.

\section{Introduction}

With a growing elderly population and a prevalence of over 200 million people worldwide (1), the global epidemic of osteoporosis (OP) poses a serious public health concern. The major medical, social, and economic consequences of osteoporosis are due to osteoporotic fractures resulting in disability (2-4) and excess mortality (5). In white populations, the lifetime risk of fragility fracture is approximately $50 \%$ in females and $20 \%$ in males (6).

In addition to fractures, other manifestations of osteoporosis such as low bone mineral density (BMD) and vertebral deformities have been strongly associated with increased risk of death from stroke (7), coronary heart diseases (8) and pulmonary diseases (9).

1. Epidemiology and database research unit, Maccabi Healthcare Services, Tel Aviv, Israel; 2. Department of Epidemiology, Merck and Co, Inc, North Wales, PA; 3. Tel Aviv University, Israel; 4. Rappaport Faculty of Medicine, Technion-Israel Institute of Technology, Haifa, Israel; 5. Institute of Hypertension, Metabolism, and Endocrinology, Tel Aviv Souraski Medical Center, Tel Aviv, Israel

Corresponding Author: Inbal Goldshtein, Maccabi Healthcare Services, 27 Ha'Mered Street Tel Aviv 68125 Israel, Tel: 9723 7952616, Fax: 97273 2132831, E-mail: goldst_in@mac.org.il
Considerable variations were observed between countries with regards to OP fracture rates (1012), warranting the need for local estimations. The reason for such variations may lie in genetic factors or environmental factors, as well as differences in measurement and reporting systems, or differences in case-finding approach. Self-report survey studies, insurance claims-data, and hospital-based studies have shown to underestimate fracture risks (13-15).

Israel has a social public health care system and developed sources of data that allow the populationbased analyses on the burden of chronic diseases that can be generalized to other western-like populations (16-19).

The available data (20-23) on the epidemiology of osteoporosis and mortality among patients with OP fractures in Israel are partial and outdated and thus may not reflect important changes in recent years such as increased life expectancy and introduction of new antiosteoporotic treatments.

The objective of the present study was to establish a registry of osteoporosis patients using automated collection of individual-level information on important characteristics (24) such as demography, co-morbid conditions, medication use, laboratory tests, and bone 
densitometry measurements. Specifically, the registry was analyzed to assess the current age-and-sex specific prevalence of osteoporosis, history of OP fractures, and a retrospective assessment of all-cause mortality among patients with OP fractures.

\section{Materials and methods}

\section{Settings}

This study utilized the longitudinal databases of Maccabi Healthcare Services (MHS), the second largest sick fund in Israel, ensuring $25 \%$ of the population with a nationwide and representative distribution. These databases are derived from electronic medical records (EMRs) of a stable population of over 2 million ensured members. Israel's sick funds provide a uniform legally defined basket of services to which every citizen is entitled as a member of one of four nationwide health funds that are financed by government via age-related capitation payments (90\% of total), patient charges and other income $(10 \%)$. Citizens are free to choose and move between health funds, which are not exclusive and must accept all applicants for memberships.

BMD measurements were collected from the datasets of a single chain of medical centers ("Assuta Health Systems"), where approximately $86 \%$ of the dualenergy X-ray absorptiometry (DXA) scans in MHS are performed. All DXA scans in these clinics are conducted using a standardized model of GE- lunar prodigy scanner.

\section{Study population}

Eligible for the study registry were all MHS members aged 18 or above with any of the following inclusion criteria: a physician diagnosis of osteoporosis (according to the International Classification of Diseases version 9 with clinical modifications (ICD-9-CM) codes: 733.0733.03, 733.09, 733.7) or osteopenia (ICD-9-CM code: 733.9) validated by any fracture one year before or after date of diagnosis, OP-specific therapy (defined by a dispensed medication prescription of any of the following: Bisphosphonates, Raloxifene, Strontium Ranelate, Teriparatide or Calcitonin), a minimum t-score of -2.5 or less, or a clinical diagnosis of a major osteoporotic fracture (MOF) or hip fracture surgery. MHS database does not include data on trauma type, except for fractures of road accidents, thus we could only partially distinguish between osteoporosis related fractures and high-impact trauma fractures. Thus, to ensure high specificity of the registry we considered only MOF for females aged 50 or above or in males aged 60 or above for independent inclusion criteria. MOF includes fractures commonly associated with osteoporosis: closed fractures of femur, vertebral, colles and proximal humerus, which were not listed in the database as associated with a car accident. Other closed fracture diagnoses may be related to osteoporosis but not considered specific enough and were used only for descriptive analysis.

Excluded from the registry were patients with Paget's disease (ICD-9-CM code 731.0, $\mathrm{n}=587$ ) or multiple myeloma (203.0, $\mathrm{n}=631$ ) as indicated in the EMR or hospital discharge, patients whose only qualifying registry entry criteria was fracture and either suffered from multiple fractures at the same date $(n=640$, most likely overwhelming trauma and not OP) or fractures due to metastatic cancer $(n=107)$, and patients whose only qualifying registry entry criteria was pamidronic or zoledronic acid purchase and who were previously diagnosed with cancer (cancer is an alternative indication to these drugs in addition to OP, $\mathrm{n}=301$ ).

Registry entry date was defined as the first medical event (diagnostic code, associated drug prescription, lab value or procedure) which is consistent with any of inclusion and all exclusion criteria.

Co-morbid conditions were defined by MHS registries for chronic major diseases such as ischemic heart disease (25), diabetes (26) and hypertension. Renal impairment at follow up was defined by last eGFR measurement $<=35$ or patient in the MHS dialysis registry. Recent depression was defined as at least 6 purchases of SSRI in the last 2 years.

Socioeconomic status (SES) was defined by the 2008 national census (27) according to the poverty index of the member's enumeration area, ranging between 1 (lowest) to 20 (highest).

\section{Study periods}

Follow up date was defined as the earliest of disenrollment from MHS, death, or December 31, 2013.

Inclusion period: between Jan 1st 2000 and Dec 31st 2013.

\section{Statistical analysis}

Age and sex specific prevalence rates were determined for December 2013. 95\% Confidence intervals for osteoporosis prevalence were calculated using the exact binomial (Pearson-Klopper) method using $\mathrm{R}$ statistical software (28).

Age-and-sex standardized morbidity ratios (SMRs) with 95\% confidence intervals were computed to compare between the OP registry and the general population of MHS.

We calculated OP incidence density rates during the study period after excluding members diagnosed with OP less than 3 years prior to first year of follow-up, as well as members with less than 5 years of continuous membership in Maccabi before diagnosis, to ensure selection of newly developed cases. For incident cases of 
osteoporosis (or MOF), only the time until cohort entry (or MOF diagnosis) contributed to the denominator of patient-years at risk.

We assessed primary incidence of MOF in MHS. Clear distinction between reports on incident events and follow-up of previous events is often difficult. High rates of surgery complications, delayed healing, recurrent complaints on past events (29), and the need for followup, may limit the accuracy of previous assessments of

\section{Table 1}

Demographics and comorbidities of osteoporosis patients with age and sex standardized morbidity ratios (SMR) compared to the general population in Maccabi healthcare services, December 2013 incidence. Thus we assessed only primary incidence, which cannot be compared to non-primary annual rates.

The study was approved by the Assuta hospital's institutional review board.

\section{Results}

A total of 118,141 eligible patients were identified for he registry, with approximately 6,000 incident cases

\begin{tabular}{|c|c|c|}
\hline & & \\
\hline \multicolumn{3}{|l|}{ Demography } \\
\hline Sex, $\%$ females & $85 \%$ & \\
\hline Age, Mean \pm SD & $69.0 \pm 11.58$ & \\
\hline SES , Mean \pm SD & $11.7 \pm 5.3$ & \\
\hline BMI, Mean \pm SD & $27.6 \pm 6.0$ & \\
\hline \multicolumn{3}{|l|}{ T-score ${ }^{4}$, Median \pm SD } \\
\hline Femur neck & $-1.9 \pm 0.8$ & \\
\hline Total hip & $-1.6 \pm 0.9$ & \\
\hline Vertebrae & $-1.8 \pm 1.3$ & \\
\hline History of prolonged $\mathrm{GC}^{5}$ use, $\%$ & $6 \%$ & \\
\hline \multicolumn{3}{|l|}{ Calendar registry entry year, n (\%) } \\
\hline$<=2001$ & $29,727(31 \%)$ & \\
\hline 2002-2004 & $18,529(19 \%)$ & \\
\hline $2005-2007$ & $15,737(16 \%)$ & \\
\hline 2008-2010 & $18,427(19 \%)$ & \\
\hline 2011-2013 & $14,988(15 \%)$ & \\
\hline \multicolumn{3}{|l|}{ Geographic district in Israel } \\
\hline Center, $\mathrm{n}$ & $66,014(68 \%)$ & \\
\hline North, $\mathrm{n}$ & $17,710(18 \%)$ & \\
\hline South, $\mathrm{n}$ & $13,682(14 \%)$ & \\
\hline Comorbidities & & SMR $(95 \% \mathrm{CI})$ \\
\hline Coronary heart disease, $\%$ & $7.5 \%$ & $1.07(1.05-1.09)$ \\
\hline Hypertension, $\%$ & $56.0 \%$ & $0.99(0.98-0.99)$ \\
\hline Diabetes, $\%$ & $19.6 \%$ & $0.90(0.89-0.92)$ \\
\hline $\mathrm{COPD}^{*}, \%$ & $6.5 \%$ & $1.32(1.28-1.35)$ \\
\hline Vitamin D Insufficiency $6, \%$ & $25.1 \%$ & $0.79(0.78-0.80)$ \\
\hline Renal impairment, $\%$ & $2.0 \%$ & $0.96(0.92-1.00)$ \\
\hline Crohn's disease, $\%$ & $2.6 \%$ & $1.54(1.48-1.60)$ \\
\hline Ulcerative Colitis, $\%$ & $10.3 \%$ & $1.25(1.22-1.27)$ \\
\hline Recent depression & $19.0 \%$ & $1.18(1.16-1.19)$ \\
\hline Obesity & $25.0 \%$ & $0.83(0.82-0.84)$ \\
\hline
\end{tabular}

OP registry

Demography

$69 \pm 11.58$

BMI, Mean \pm SD

$-1.9 \pm 0.8$

$-1.8 \pm 1.3$

Vertebrae

$18,529(19 \%)$

$15,737(16 \%)$

2011-2013

$66,014(68 \%)$

(18\%)

South, $\mathrm{n}$

Chronic obstructive pulmonary disease; 3. Socioeconomic status, ranging between 1 (lowest) to 20 (highest). See text for details; 4 . Latest available measurement;

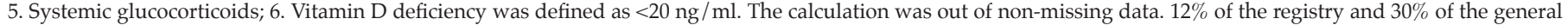
population in Maccabi had missing vitamin D level. 
annually (table 1). The mean duration of follow-up since first indication of osteoporosis was 7.9 years $(\mathrm{SD}=4.5)$. A total of $66 \%$ of the registry's patients met two or more inclusion criteria, validating their OP status (Appendix A).

\section{Prevalence and incidence rates in MHS}

The crude prevalence rates of osteoporosis among members aged 50 or above in MHS were $31.4 \%$ and $5.9 \%$ among females and males, respectively (table 2). Prevalence of MOF history increased exponentially with age reaching $30.1 \%$ in females and $11.8 \%$ in males at the age of 85 years or above (table 3 ).

Figure 1a

Age and sex specific incidence density rates and 95\% confidence intervals of osteoporosis (per 1000 person years) in Maccabi healthcare services, 2003-20137

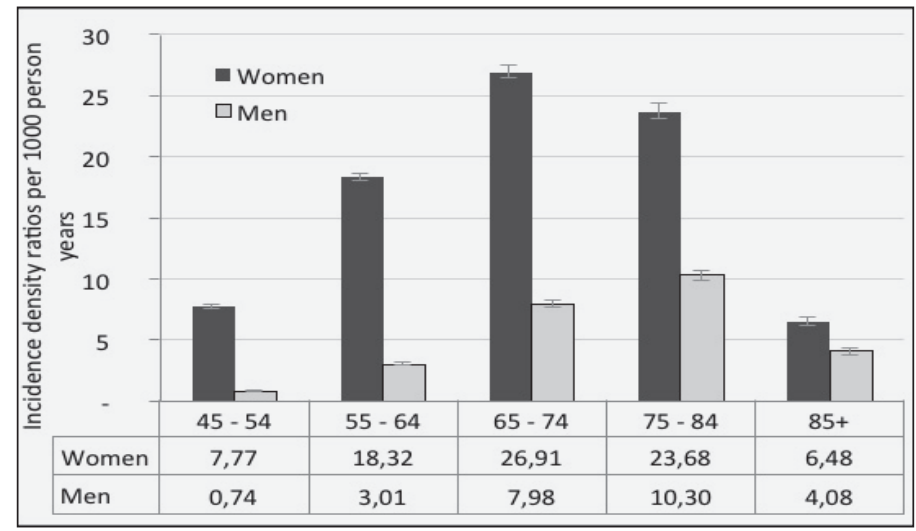

7. Error bars indicate $95 \%$ confidence intervals.

The highest incidence rate of $\mathrm{OP}$ was recorded at the age group of 65-74 and 55-64 among males and females, respectively (figure 1.a). The risk of $\mathrm{MOF}$ increases with age (figure 1.b).

\section{Demographics and comorbidities of OP registry patients}

In 2013, the mean age of OP patients in MHS was 69.0 years old $(\mathrm{SD}=11.6)$, with females accounting for $85 \%$ of the registry (table 1). Compared with the age and sex adjusted general population of MHS, OP patients were more likely to have diagnosed history of COPD, Crohn's disease, ulcerative colitis, and recent depression, and less likely to be obese, diabetic or have vitamin $\mathrm{D}$ insufficiency.

Figure $\mathbf{1 b}$

Annual age and sex specific incidence (per 1000 capita) of primary major osteoporotic fractures in Maccabi healthcare services, 2013

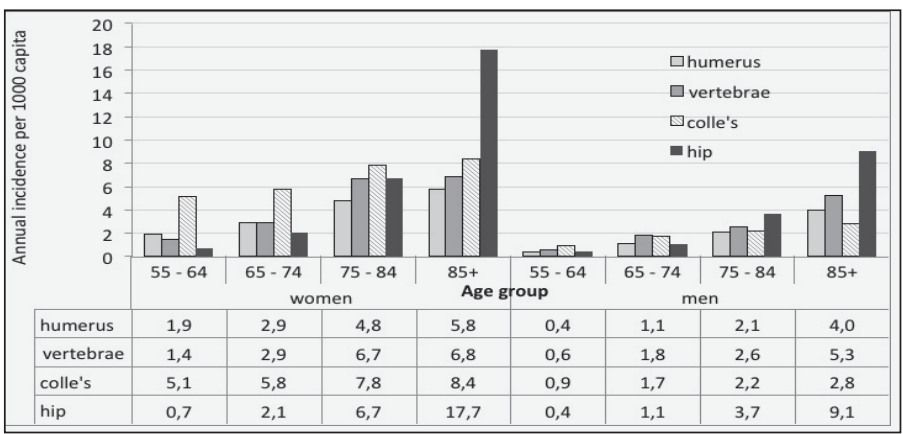

History of fractures in OP registry

Among OP patients with an indication of MOF history $(29 \%)$, the most common fractures were hip among males (36.2\%) and colle's among females (37.3\%).

In addition, in $12 \%$ of the registry, we found an indication of non-MOF fractures that are likely to be related with osteoporosis (e.g. metatarsal, ribs, and ankle) which were not inclusion criteria for the registry.

\section{All-cause Mortality after OP fracture}

Figure 1 depicts all-cause mortality rates within 1 year from date of MOF. The highest mortality rates $(23 \%$ in females and $32 \%$ in males) were observed among elderly patients ( 85 year or above) with a hip fracture.

\section{Anti-osteoporosis therapy}

A total of $72 \%$ of the registry had at least one dispensation of osteoporosis medication ever. Among incident cases, treatment initiation rates were significantly higher $(\mathrm{P}<0.001)$ in females $(75.3 \%)$ compared to males $(62.1 \%)$. Only $24 \%$ of patients with hip fracture who were Anti-osteoporosis therapy naïve, initiated treatment after the fracture occurrence ( $22 \%$ were already treated before fracture event). This

Table 2

Age and sex specific prevalence rates per 1000 and 95\% confidence intervals of osteoporosis in Maccabi healthcare services, Israel, 2013

\begin{tabular}{|c|c|c|c|c|c|c|c|c|}
\hline Age group & 18- 45 & $45-54$ & $55-64$ & $65-74$ & $75-84$ & $85+$ & Total age $18+$ & $\begin{array}{l}\text { age } 50+\text { females } \\
\& \text { age } 60+\text { males }\end{array}$ \\
\hline Males & $3.2(3-3.4)$ & $9.7(8.9-10.5)$ & $26.8(25.8-27.9)$ & $91.7(89.2-94.2)$ & $173.4(168.6-178.1)$ & $244.6(234.3-255.1)$ & $23.3(22.9-23.7)$ & $97.9(96.3-99.6)$ \\
\hline Females & $6.7(6.5-7.0)$ & $70.3(68.2-72.5)$ & $238.5(235.8-241.2)$ & $462.6(458.6-466.6)$ & $600.1(594.6-605.6)$ & $622.1(613.1-631.0)$ & 117.1 (116.4-117.9) & $314(312.2-315.8)$ \\
\hline
\end{tabular}


Table 3

Age and sex specific prevalence rates (per 1000) of major osteoporotic fractures in Maccabi healthcare services, Israel, 2013

\begin{tabular}{|c|c|c|c|c|c|c|c|}
\hline & & \multicolumn{6}{|c|}{ Age } \\
\hline \multirow[t]{2}{*}{ Spine } & Males & 0.0 & 1.4 & 10.5 & 18.7 & 29.4 & 5.8 \\
\hline & Females & 1.6 & 8.4 & 21.3 & 49.8 & 72.1 & 17.7 \\
\hline Humerus & Males & 0.0 & 0.9 & 6.0 & 13.1 & 22.6 & 3.8 \\
\hline Hip & Females & 0.7 & 3.8 & 11.3 & 42.0 & 133.9 & 15.29 \\
\hline \multirow[t]{2}{*}{ Colles } & Males & 0.02 & 2.1 & 11.0 & 17.3 & 25.3 & 5.94 \\
\hline & Females & 6.7 & 28.1 & 51.4 & 75.1 & 94.1 & 37.37 \\
\hline Any of the above & Males & 0.1 & 5.4 & 32.7 & 64.7 & 118.1 & 20.0 \\
\hline
\end{tabular}

proportion is higher after vertebral fractures $(38 \%)$ and lower after colles or humerus fractures $(21 \%)$.

\section{Figure 2}

Age and sex specific all-cause mortality rates within 1 year from osteoporotic fracture event, Maccabi healthcare services, Israel, 2000-2013

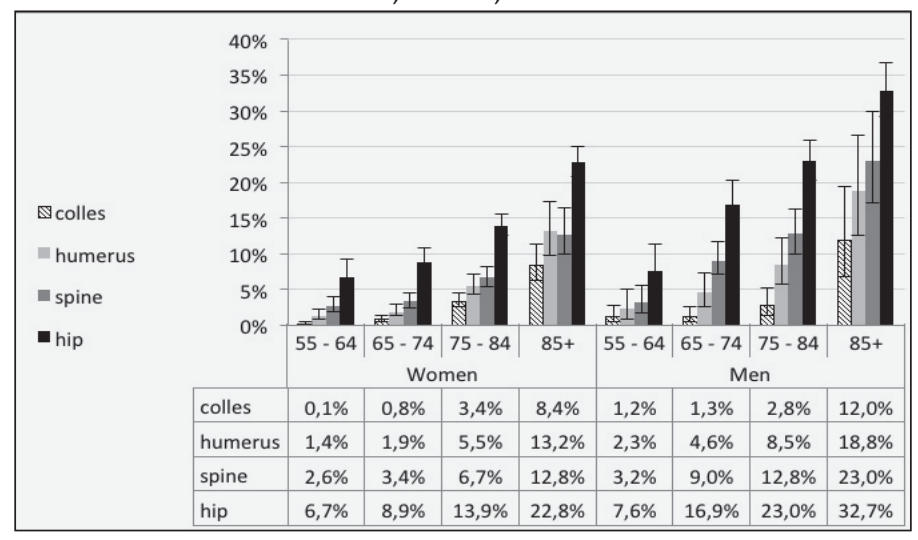

\section{Bone density measurements}

Approximately $72 \%$ of the OP registry patients had an indication of performing a DXA scan. BMD values were electronically available for $52 \%$ of them $(37 \%$ of the total registry). Among the patients with t-scores of -2.5 or lower: $55 \%$ were $<=-2.5$ at femoral neck, $40 \%$ at spine and 5\% total hip. In all but 3\% $(n=406)$ the femur neck indicated at least osteopenia. Mean values of DXA measurements at follow-up are given in table 1.

\section{Discussion}

The present study described the establishment of an osteoporosis patient registry in a large and representative health organization in Israel, and the first population- based report of the epidemiology of this disease in the country.

The results of the study reveal the immense burden of osteoporosis in Israel, with prevalence rates of $61 \%$ and $19 \%$ among females and males aged 75 or above. The observed OP prevalence was comparable to the findings of other large registries in Europe such as "BEST" (30) and "BoneEVA" (31). An Israeli survey (23) reported a lower prevalence (32\% vs. $49 \%$ among females aged 65 ), possibly explained by the limitation of self-report data, as well as reduced awareness at that period (1999). The prevalence of diagnosed OP concords with a previous Israeli study (22) (14\% vs. 13\% among females aged 45-74, results not shown).

In Israel, the remaining life expectancy of men and women at age 50 is approximately 31 and 35 years, respectively (CBS 2014). Therefore, according to our age-specific prevalence, the respective estimated OP-fracture lifetime risks in Israeli men and women are $6 \%$ and $30 \%$,in accordance with previous international assessments $(32,33)$. Similar to previous large cohort studies $(34,35)$ our results indicate that while the absolute risk of hip fractures is two-fold higher among females, they account for a greater proportion of MOF among males. Similar to previous studies $(36,37)$, men were found to have a significantly poorer survival after hip fracture compared to women, although residual confounding by co-morbid conditions should be examined in future studies.

In agreement with previous analyses among OP patients, we found increased SMRs for known risk markers such as COPD (38) and inflammatory bowel disease (IBD) (39) compared to the general population. Obesity and diabetes were decreased in the OP registry compared to the general population of MHS, with a BMI distribution similar to a recent large US cohort (40).

This study has several major strengths such as a large 
and unselected population, a relatively long retrospective follow-up, standardized densitometry measurements, and automated collection of comprehensive data, including medical diagnosis, prescribed therapies, and lab tests. To our knowledge, this is the first registry of its kind in Israel, and one of the largest worldwide. We plan to update it periodically, identify new cases that meet the selection criteria in MHS and monitor outcomes.

Some limitation should be discussed, such as missing data on fracture circumstances, specifically to distinguish between OP related vs. high-impact trauma fractures. Our objective was high specificity of the registry, thus only typical/characteristic OP fractures were used as independent inclusion criteria, and multiple concurrent fractures were excluded (rarely OP-related, previously assessed as $2.5 \%$ of OP fractures (21)). In addition, predefined age cut-offs were used to identify MOF. The asymmetric age cut-offs between males and females $(60+$ vs. $50+$ respectively) may yield somewhat lower sensitivity to detect males compared to females. Similarly to other retrospective population-based studies relying on clinical diagnoses, our data is likely to underestimate the rates of vertebral compression fractures (6), as these fractures are universally underdiagnosed.

Building a valid and efficient algorithm to detect patients for a central registry requires careful examination and assessment of the variety of different measures and definitions (41). The majority of the registry was validated by meeting at least 2 inclusion criteria. The remainder may be explained by low awareness for documentation and treatment initiation, non-compliance of patients, partial electronic availability of bone density values, or (less frequently) due to contra-indication of therapy.

We believe this up-to-date registry can serve as a valuable resource for future studies in the field of osteoporosis and improve our understanding of the risks and prevention of osteoporosis.

\section{Funding: The study was funded by Merck and Co.}

Conflict of interest: Sofia Ish-Shalom has received research grants and consulting, advisory board, lecture fees, and any combination of the three from Merck Sharp \& Dohme, Eli Lilly, Enterabio, GlaxoSmithKline, and Novartis. Vanessa Rouach has received lecture fees from Eli Lilly, GlaxoSmithKline, and Novartis. Julie Chandler and Allison Martin Nguyen are employees of Merck and Co. Inbal Goldshtein, Varda Shalev and Gabriel Chodick declare that they have no conflict of interest.

Acknowledgments: We would like to thank Mrs. Racheli Katz and Mrs. Esma Herzel of Meaccbi Healthcare Services, for their considerable contribution to data collection. This work was performed in partial fulfillment of the requirements for a Ph.D. degree of Mrs. Inbal Goldshtein, Faculty of Management, Tel Aviv University, Israel.

\section{References}

1. Cooper C, Campion G, Melton LJ, 3rd.Hip fractures in the elderly: a worldwide projection. Osteoporos Int 1992;2:285-289

2. Cummings SR, Melton LJ. Epidemiology and outcomes of osteoporotic fractures. Lancet 2002;359 (9319):1761-1767.

3. Gullberg B, Johnell O, Kanis JA. World-wide projections for hip fracture. Osteoporos Int 1997;7 (5):407-413
4. Johnell O, Kanis JA. An estimate of the worldwide prevalence, mortality and disability associated with hip fracture. Osteoporos Int 2004;15:897-902.

5. Abrahamsen B, van Staa T, Ariely R, Olson M, Cooper C. Excess mortality following hip fracture: a systematic epidemiological review. Osteoporos Int 2009;20:1633-1650.

6. Sambrook P, Cooper C. Osteoporosis. Lancet 2006;367:2010-2018.

7. Nordstrom A, Eriksson M, Stegmayr B, Gustafson Y, Nordstrom P. Low bone mineral density is an independent risk factor for stroke and death. Cerebrovasc Dis 2010;29:130-136.

8. Kado DM, Browner WS, Blackwell T, Gore R, Cummings SR. Rate of bone loss is associated with mortality in older women: a prospective study. J Bone Miner Res 2000;15:1974-1980.

9. Hasserius R, Karlsson MK, Nilsson BE, Redlund-Johnell I, Johnell O. Prevalent vertebral deformities predict increased mortality and increased fracture rate in both men and women: a 10-year population-based study of 598 individuals from the Swedish cohort in the European Vertebral Osteoporosis Study. Osteoporos Int 2003;14:61-68.

10. Dhanwal DK, Cooper C, Dennison EM. Geographic variation in osteoporotic hip fracture incidence: the growing importance of asian influences in coming decades. J Osteoporos 2010:757102.

11. Elffors I, Allander E, Kanis JA, Gullberg B, Johnell O, Dequeker J, Dilsen G, Gennari C, Lopes Vaz AA, Lyritis G, et al. The variable incidence of hip fracture in southern Europe: the MEDOS Study. Osteoporos Int 1994;4:253263

12. Ismail AA, Pye SR, Cockerill WC, Lunt M, Silman AJ, Reeve J, Banzer D, Benevolenskaya LI, Bhalla A, Bruges Armas J, Cannata JB, Cooper C, Delmas PD, Dequeker J, Dilsen G, Falch JA, Felsch B, Felsenberg D, Finn JD, Gennari C, Hoszowski K, Jajic I, Janott J, Johnell O, Kanis JA, Kragl G, Lopez Vaz A, Lorenc R, Lyritis G, Marchand F, Masaryk P, Matthis C, Miazgowski T, Naves-Diaz M, Pols HA, Poor G, Rapado A, Raspe HH, Reid DM, Reisinger W, Scheidt-Nave C, Stepan J, Todd C, Weber K, Woolf AD, O'Neill TW. Incidence of limb fracture across Europe: results from the European Prospective Osteoporosis Study (EPOS). Osteoporos Int 2002;13:565-571.

13. Gerdhem P, Akesson K. Rates of fracture in participants and non-participants in the Osteoporosis Prospective Risk Assessment study. J Bone Joint Surg Br 2007

14. Smith MR, Lee WC, Brandman J, Wang Q, Botteman M, Pashos CL. Gonadotropin-releasing hormone agonists and fracture risk: a claimsbased cohort study of men with nonmetastatic prostate cancer. J Clin Oncol 2005;23:7897-7903.

15. Unnanuntana A, Gladnick BP, Donnelly E, Lane JM. The assessment of fracture risk. J Bone Joint Surg Am 2010;92:743-753.

16. Bellamy L, Casas JP, Hingorani AD, Williams D. Type 2 diabetes mellitus after gestational diabetes: a systematic review and meta-analysis. Lancet 2009;373:1773-1779

17. Chodick G, Elchalal U, Sella T, Heymann AD, Porath A, Kokia E, Shalev V The risk of overt diabetes mellitus among women with gestational diabetes: a population-based study. Diabet Med 27:779-785

18. Chodick G, Shalev V, Gerber Y, Heymann AD, Silber H, Simah V, Kokia E. Long-term persistence with statin treatment in a not-for-profit health maintenance organization: a population-based retrospective cohort study in Israel. Clinical therapeutics 2008;30:2167-2179

19. Mann DM, Woodward M, Muntner P, Falzon L, Kronish I Predictors of nonadherence to statins: a systematic review and meta-analysis. The Annals of pharmacotherapy 44:1410-1421

20. Givon U. Consensus conference on the treatment and rehabilitation of hip fractures in the elderly. Isr Med Assoc 1999; 1:131-136

21. Liel Y, Castel H. [Incidence of osteoporotic fractures in southern Israel]. Harefuah 2004;143:18-21

22. Nitzan-Kaluski D, Chinich A, Ifrah A, Merom D, Green M. Correlates of osteoporosis among Jewish and Arab women aged 45-74 in Israel: national women's health interview survey. The journal of gender-specific medicine 2002;6:17-23

23. ICDC, Ministry of Health (2004) National Health Survey in Israel - a WHO project, European Sector. EUROHIS 2004 publication no 237.

24. David C, Confavreux CB, Mehsen N, Paccou J, Leboime A, Legrand E (2010) Severity of osteoporosis: what is the impact of co-morbidities? Joint Bone Spine 2010;77 Suppl 2:S103-106.

25. Shalev V, Chodick G, Goren I, Silber H, Kokia E, Heymann AD. The use of an automated patient registry to manage and monitor cardiovascular conditions and related outcomes in a large health organization. Int J Cardiol 2011;152:345-349.

26. Chodick G, Heymann AD, Shalev V, Kookia E. The epidemiology of diabetes in a large Israeli HMO. Eur J Epidemiol 2003;18:1143-1146

27. Israel Central Bureau of Statistics (2013) Characterization of geographical units by the socio-economic level of the population 2008. http://www.cbs.gov.il/webpub/pub/text_page_eng. html?publ=100\&CYear=2008\&CMonth=1 Accessed 19 October 2014

28. Friedman DS, Quigley HA, Gelb L, Tan J, Margolis J, Shah SN, Kim EE Zimmerman T, Hahn SR. Using pharmacy claims data to study adherence to glaucoma medications: methodology and findings of the Glaucoma Adherence and Persistency Study (GAPS). Invest Ophthalmol Vis Sci 2007;48 
:5052-5057.

29. Donaldson LJ, Reckless IP, Scholes S, Mindell JS, Shelton NJ. The epidemiology of fractures in England. J Epidemiol Community Health 2008;62:174-180.

30. Hadji P, Klein S, Gothe H, Haussler B, Kless T, Schmidt T, Steinle T, Verheyen F, Linder R. The epidemiology of osteoporosis--Bone Evaluation Study (BEST): an analysis of routine health insurance data. Dtsch Arztebl Int 2013;110:52-57.

31. Haussler B, Gothe H, Gol D, Glaeske G, Pientka L, Felsenberg D. Epidemiology, treatment and costs of osteoporosis in Germany--the BoneEVA Study. Osteoporos Int 2007;18:77-84.

32. Holroyd C, Cooper C, Dennison E. Epidemiology of osteoporosis. Best Pract Res Clin Endocrinol Metab 2008;22 (5):671-685.

33. Hopkins RB, Pullenayegum E, Goeree R, Adachi JD, Papaioannou A, Leslie WD, Tarride JE, Thabane L. Estimation of the lifetime risk of hip fracture for women and men in Canada. Osteoporos Int 2012;23:921-927.

34. Brauer CA, Coca-Perraillon M, Cutler DM, Rosen AB. Incidence and mortality of hip fractures in the United States. JAMA 2009;302:1573-1579.

35. Feldstein A, Elmer PJ, Orwoll E, Herson M, Hillier T. Bone mineral density measurement and treatment for osteoporosis in older individuals with fractures: a gap in evidence-based practice guideline implementation. Arch Intern Med 2003;163:2165-2172.

36. Bliuc D, Nguyen ND, Milch VE, Nguyen TV, Eisman JA, Center JR. Mortality risk associated with low-trauma osteoporotic fracture and subsequent fracture in men and women. JAMA 2009;301:513-521.

37. Center JR, Nguyen TV, Schneider D, Sambrook PN, Eisman JA. Mortality after all major types of osteoporotic fracture in men and women: an observational study. Lancet 1999;353:878-882.

38. Lehouck A, Boonen S, Decramer M, Janssens W. COPD, bone metabolism, and osteoporosis. Chest 2011;139:648-657.

39. Bernstein CN, Blanchard JF, Leslie W, Wajda A, Yu BN. The incidence of fracture among patients with inflammatory bowel disease: a populationbased cohort study. Annals of internal medicine 2000;133:795-799

40. O'Malley C, Tran N, Zapalowski C, Daizadeh N, Olenginski T, Cauley J. Multimorbidity in women with and without osteoporosis: results from a large US retrospective cohort study 2004-2009. Osteoporosis International: 2014;1-14

41. Gliklich R, Dreyer N. Registries for Evaluating Patient Outcomes. Agency for Healthcare Research and Quality, Rockville, MD, 2010

\section{Appendix A}

Distribution of inclusion criteria in the Maccabi healthcare services osteoporosis registry

Inclusion criteria met

1. OP diagnosis + medication + OP fracture

2. OP diagnosis + medication or + pathologic BMD

3. OP diagnosis + OP fracture

4. Medication + OP fracture Or + pathologic BMD

5. BMD alone or BMD+OP fracture

6. Medication alone

7. OP diagnosis alone

8. OP fracture alone n

15,169

54,345

4,396

2,766

1,038

14,253

13,517

12,657
$\%$ of registry

$13 \%$

$46 \%$

$4 \%$

$2 \%$

$1 \%$

$12 \%$

$11 \%$

$11 \%$ 